\title{
GEOGRAFÍA SIN TOGA Y SIN PIZARRÓN
}

\author{
Ana María Liberali \\ Doctorado en Ciencias Sociales. Universidad Nacional de Luján. \\ Luján (Provincia de Buenos Aires, Argentina) \\ Correo electrónico: amliberali@gmail.com/
}

Recibido: 2 de marzo de 2011. Aceptado: 23 de marzo de 2011.

\section{RESUMEN}

No es novedad la posibilidad de aprender Geografía a través de obras que no han sido escritas en medios académicos formales, pero que sin duda reflejan con gran precisión una serie de problemáticas que los geógrafos "académicos" intentamos conceptualizar, no siempre con buen éxito. En este trabajo trataremos de nutrirnos de las vivencias geográficas que viajeros, escritores, poetas, compositores, pintores y cineastas trasmiten como nadie a alumnos sin delantal.

Palabras clave: Geografía, educación, arte, películas, canciones.

\begin{abstract}
It is known the possibility of learning Geography through works that have not been written in formal academic means, but that without a doubt not always reflects with high accuracy a series of problematic which "the academic" geographers we tried to generate concepts, with good success. In this work we will try to nourish ourselves of the geographic experiences that travelling, writers, poets, composers, painters and film directors pass on like anybody to students without school apron.
\end{abstract}

Key words: Geography, education, art, films, songs.

\section{GEOGRAFÍA EN LAS PELÍCULAS}

Díganme cómo es

(palabras del ciego de Amarcord, a sus compañeros de bote)

\section{De Marco Polo a Full Monty}

Si bien los viajes de Marco Polo no han sido las primeras expresiones informales, son, sin duda, una importantísima síntesis geográfica del mundo de la época. Los relatos de viajeros y los libros de navegación se han destacado por expresar con más fuerza una serie de connotaciones tanto físicas, humanas como económicas que los fríos números y los planos mapas no han podido lograr.

Tampoco Full Monty[1] es la última expresión cinematográfica, pero constituye un paradigma de la situación socioeconómica mundial, que sacude tanto a países centrales como periféricos, y que consiste en la problemática del desempleo. Se trata de la crisis 
de la industria siderúrgica en el pueblo de Sheffield (Reino Unido) y las opciones posibles para subsistir llegando al extremo de convertirse en "streapers".

Este film está absolutamente relacionado con otra obra, cuyo título original es Brassed Off, traducida como Tocando el Viento [2] y que refleja la misma situación en las minas de carbón (actividad concatenada con la industria del acero), en un pueblo imaginario de Yorkshire, Inglaterra, en la época del gobierno conservador de Margaret Thatcher.

Otro ejemplo emblemático lo constituye la película argentina Un Lugar en el Mundo[3], que fuera filmada en la provincia de San Luis, pero que sin duda puede corresponder a cualquier parte del globo. Trata sobre el impacto de las multinacionales sobre una economía ganadera marginal, desde ya amparadas por la burguesía local, que se conforma con las migajas de los grandes negocios.

La Deuda Interna[4] es otra película que pone sobre el tapete las grandes diferencias socio-territoriales en la Argentina (incluso dentro de una misma provincia como es el caso de Jujuy), donde se muestra también cuáles han sido las principales víctimas del hundimiento del buque de la Armada Gral. Belgrano, durante la Guerra de Malvinas.[5]

Las cuestiones fronterizas nunca mejor representadas que por Traffic[6], donde se muestran los negocios non santos entre EEUU y México y sus implicancias sociales.

\section{Una botella de Coca Cola}

El Desierto del Kalahari es una de las zonas más inhóspitas del sur de África. Su tamaño, para hacerse una idea es mayor que España y ocupa los territorios de Botswana, Namibia y Sudáfrica. Al Norte lo limita el río Okavango, el Orange por el Sudoeste, y por el este el Zambezi. Por el nordeste cierran paso a sus arenas los Pantanos de Makgadidgadi. La vegetación del Kalahari es mínima porque el agua escasea, pero increíblemente hay una abundante fauna y parece que así fue durante siglos tal y como lo atestiguan las pinturas rupestres de las Colinas Tsodilo. Aunque el Kalahari es una tierra de nadie, allí se refugiaron los bosquimanos, antiguos pobladores del territorio de Botswana, que fueron desplazados al desierto. Este pueblo, es el único que puede sobrevivir en un medio tan hostil. Una visita al desierto implica ir bien surtido de agua ya que en condiciones extremas de calor el cuerpo puede consumir cerca de nueve litros de agua al día por efecto de la deshidratación. La película Los Dioses deben estar Locos[7] nos muestra no solamente estos aspectos físicos de extrema aridez, sino fundamentalmente la cuestión cultural. Al caer un envase de Coca Cola desde una avioneta, los bosquimanos piensan que es un objeto enviado por los Dioses. Buscan diferentes utilidades, que de hecho encuentran y, por ser un elemento único, se generan disputas que jamás habían tenido. Es así como envían a un miembro del grupo a devolver este elemento que traía discordia, al fin de la tierra: la costa. El hombre atraviesa diferentes espacios hasta llegar a la ciudad de Johannesburgo, donde se pone de manifiesto el antípodas entre la cultura urbana y la bosquimana.

\section{La escena del ciego}


Amarcord es un film de Fellini donde se hace una simple descripción del acontecer cotidiano de un pueblo de Italia, de su propio pueblo. La presentación es, por momentos, grotesca, pero pretende mostrar la realidad de ese o de cualquier otro pueblo chico en cualquier parte del mundo.

Reconozco no haber comprendido en el momento en que la viera, una escena referida a la presencia de un enorme buque que fondeaba cerca de la costa. Todos querían ir a verlo iluminado, hasta un ciego, que pidió que lo llevaran en las lanchas, como a los demás, y que le contaran cómo era. Pensé que se trataba de un símbolo típico de Fellini. Sin embargo, años después, durante mi estancia en la ciudad de Ushuaia, que contaba entonces con sólo 8000 habitantes, se repitió el acontecimiento descripto por Fellini. Llegó a la Bahía el trasatlántico Eugenio $C$, con 2000 pasajeros (un cuarto de la población de Ushuaia). Y pasó lo mismo, todos fuimos esa noche a la costanera, a pesar del frío, a ver las luces del barco...

Nuestros amigos de la banca[8] es una perfecta clase de Geografía Económica. No tiene actores, o sí, los actores son los personajes verdaderos del Fondo Monetario Internacional, del Banco Mundial y del gobierno de Uganda. Es una documental que nos deja sin palabras porque muestra sin tapujos de qué manera se definen las políticas en los países periféricos y cómo los gobiernos se transforman en nexos de los grandes centros de poder.

\section{GEOGRAFÍA EN EL CANCIONERO}

Turbio fondeadero donde van a recalar, barcos que en el muelle para siempre han de quedar...

Sombras que se alargan en la noche del dolor; náufragos del mundo que han perdido el corazón...

Puentes y cordajes donde el viento viene a aullar, barcos carboneros que jamás han de zarpar...

(Niebla del Riachuelo, letra de Enrique Cadícamo)

\section{De un pueblo "mediterráneo" al mar Mediterráneo...}

Colgado de un barranco

duerme mi pueblo blanco,

bajo un cielo, que a fuerza de no ver nunca el mar,

se olvidó de llorar...

En sus callejas de polvo y piedra,

por no pasar, ni pasó la guerra.

Sólo el olvido

camina lento, bordeando la cañada,

donde no crece una flor

ni trashuma un pastor.

El sacristán ha visto hacerse viejo al cura,

el cura ha visto al cabo,

y el cabo al sacristán... 
Y mi pueblo después

vio morir a los tres.

$Y$ me pregunto por qué

nace la gente

si nacer o morir es

indiferente.

Las descripciones de Joan Manuel Serrat referentes a un pueblo en medio de la extrema aridez española[9] y, por otra parte, del mar Mediterráneo, son otros ejemplos de cómo hacer Geografía sin pizarrón.

Pueblo Blanco no es más que un paradigma de una población que ha quedado en medio del desierto siendo afuncional para los nuevos tiempos, y que además de los lógicos inconvenientes de la falta de agua, carece de futuro.

De la siega a la siembra

se vive en la taberna.

Las comadres murmuran

su historia en el umbral,

y las muchachas hacen bolillos

buscando ocultas tras los visillos

a ese hombre joven

que, noche a noche, forjaron en su mente.

Fuerte pa ser su señor,

y tierno para el amor...

Ellas sueñan con él,

y él con irse muy lejos

de su pueblo, y los viejos

sueñan morir en paz.

Todo es pasado y la emigración de jóvenes, en especial de hombres, es imposible de contener.

$Y$ morir por morir, quieren morirse al sol,

la boca abierta al calor,

como lagartos,

y medio ocultos tras un sombrero de esparto...

Escapad, gente tierna,

que esta tierra está enferma.

No pidas al mañana

lo que no te dio ayer,

que no hay nada que hacer...

Coge tu mula, tu hembra y tu arreo,

sigue el camino del pueblo hebreo.

Busca otra luna,

tal vez mañana sonría la fortuna.

En el Noroeste Argentino existen pueblos como el de referencia, donde sólo quedan los viejos y muchas casas permanecen cerradas con candados desde hace muchos años... Se los denomina pueblos fantasmas y pierden población de manera absoluta en cada censo. 
$Y$ si te toca llorar,

es mejor frente al mar...

La necesidad de estar frente al mar, no es sólo una consecuencia de la falta de agua, sino que es la ambición de quienes sienten la mediterraneidad como un encierro. También se expresa en la película La Deuda Interna, donde el protagonista siendo niño ve el salar y se imagina el mar[10].

Si yo pudiera unirme

a un vuelo de palomas

y atravesando lomas,

dejar mi pueblo atrás,

juro por lo que fui

que me iría de aquí.

Pero los muertos están en cautiverio,

y no nos dejan salir del cementerio...

En todos estos casos, el cementerio es más grande que el pueblo.

Lo contrario ocurre con quien nació a la vera del mar, quien pretende no apartarse nunca de él, independientemente de sus penas o del lugar donde le tocara vivir[11].

Quizá porque mi niñez

sigue jugando en tu playa

y escondido tras las cañas

duerme mi primer amor...

Llevo tu luz y tu olor

por donde quiera que vaya [12]

y amontonado en tu arena

guardo amor, juegos y penas.

Yo en la piel tengo el sabor

amargo del llanto eterno,

que han vertido en ti cien pueblos,

de Algeciras a Estambul,

para que pintes de azul

sus largas noches de invierno.

A fuerza de desventuras

tu alma es profunda y oscura,

A tus atardeceres rojos

se acostumbraron mis ojos

como el recodo al camino.

Soy cantor, soy embustero

me gusta el juego y el vino

tengo alma de Marinero.

Que le voy a hacer si yo

nací en el Mediterráneo...

$Y$ te acercas y te vas

después de besar mi aldea

jugando con la marea

te vas pensando en volver, 
eres como una mujer

perfumadita de brea.

Que se añora y que se tiene

que se conoce y se teme,

“(...) te vas pensando en volver", tal cual lo hicieron quienes vinieron a América por necesidad, inculcando la idea del retorno en las siguientes generaciones.

Si un día para mi mal,

viene a buscarme la Parca,

empujad al mar, mi barca

con un levante otoñal.

$Y$ dejad que el temporal

desguace sus alas blancas.

$Y$ a mi enterradme sin duelo

entre la playa y el cielo,

en la ladera de un monte

más alto que el horizonte.

Quiero tener buena vista...

Mi cuerpo será camino,

le daré verde a los pinos

y amarillo a las genistas.

Cerca del mar porque yo

nací en el Mediterráneo.

No elegimos dónde queremos nacer, pero casi siempre elegimos dónde queremos morir. Contrariamente al caso del pueblo mediterráneo, los habitantes del mar Mediterráneo sueñan permanecer en su lugar de origen, aun después de la muerte.

\section{Tango y Geografía}

A fines del siglo XIX y principios del XX, la Argentina se integró al sistema económico mundial como productora de cueros, lanas, carnes y cereales. Esta inserción trajo aparejada una serie de modificaciones a nivel territorial y social. Eran necesarios brazos que hicieran el trabajo rural y, a la vez, que construyeran la infraestructura necesaria para el funcionamiento del nuevo modelo.

Ya no había en la región Pampeana ni población negra ni indígena que fuera funcional a esta actividad, razón por la cual se abrió la inmigración a europeos del sur, que se encontraban pasando por una grave crisis económica. Primeramente se otorgaron tierras a las familias que ingresaban a nuestro territorio, pero posteriormente, las condiciones fueron cambiando y gran parte de los inmigrantes terminaron asentándose en las ciudades puertos, en muchos casos hacinados y en condiciones de verdadera marginalidad.

Es en este contexto donde surge, como marginal y mal visto por la elite local, el tango, que a través del tiempo fue pasando de los arrabales a los salones, y es hoy la música que nos representa en todo el mundo. 
Gran parte de esa Gran Inmigración que modificó en forma trascendente la sociedad argentina, vino temporariamente con la intención de hacerse la América y volver a su tierra natal. En la mayoría de los casos esto no fue posible quedando muchas ilusiones frustradas, tanto materiales como espirituales, parejas y familias separadas por la imposibilidad del regreso, sintiéndose amarrados [13] y sin recursos:

Vago como una sombra atormentada

bajo el gris de la recova[14],

me recuerdo y no soy nada...

Soy como mi barca carbonera

que ha quedado recalada

y vive atada a la ribera.

Yo, también atado a mi pasado,

soy un barco que está anclado

y siento en mis carnes sus amarras

como garfios, como garras...

Lloro aquellos días

que jamás han de volver.

Sueño aquellos besos

que jamás he de tener.

Soy como mi lancha carbonera

que ha quedado en la ribera,

no parte más! [15]

Muchos otros tangos tratan este tema y describen a la Buenos Aires de esos tiempos, con ríos y arroyos que hoy en día están entubados o esquinas famosas por la presencia del malevaje o las prostitutas de origen francés.

Sur y Barrio de Tango [16], Nieblas del Riachuelo[17], Barrio de Flores[18], constituyen entre muchos otros una verdadera Geografía Histórica de Buenos Aires.

En la actualidad, los tangos que más reflejan a nuestra ciudad, entre otros, son Balada para un Loco y Chiquilín de Bachín[19], Café La Humedad[20], Corazón mirando al Sur[21], y ¿En qué esquina te encuentro Buenos Aires?[22]:

Este último es un poema mucho más extenso de Florencio Escardó, donde se describe la casi totalidad de Buenos Aires. Al ponerle música de tango, Héctor Stamponi eligió sólo algunos de esos versos.

Ya no sirve Corrientes y Esmeralda, no están solos. ni esperan los porteños.

Seguro estoy de hallarte donde sea.

en Núñez o en Palermo

en las casas de patios con jazmines

y en los nuevos y antiguos rascacielos,

o en la última esquina sin ochava

de un San Telmo sin negros.

El autor intenta buscar la esencia del nuevo Buenos Aires. 
En qué esquina te encuentro Buenos Aires...?

En Callao y Quintana mundo ajeno,

Esta esquina corresponden al barrio de mayor poder adquisitivo de Buenos Aires: la Recoleta.

Tal vez en Mataderos. en la esquina

donde junta leguas El Resero,

En el barrio de Mataderos, un barrio obrero cercano al frigorífico, se ha erigido la estatua de un resero, y hace referencia a una realidad socio-económica opuesta a la de la Recoleta, destacando así Escardó las desigualdades internas de la ciudad de Buenos Aires.

O cerca de la estatua de Florencio

o rumbo del Abasto por Salguero.

Donde anduvo Gardel, silbando tangos

que aguantaron el tiempo

y algunos que no oís porque murieron.

Aquí contrapone la expresión de las letras y las artes, ya que la estatua de Florencio Sánchez (destacado escritor) se encontraba en la puerta del Teatro San Martín[23] con el Abasto, donde estaba el mercado de concentración de frutas, verduras y otras mercaderías, caracterizado por los conventillos y la falta de instrucción de quienes trabajaban allí.

En qué esquina te encuentro Buenos Aires...?

En qué esquina te encuentro?

En la esquina de Sábato y Pichucho

$o$ en la esquina de Borges y Carriego.

Las esquinas de Sábato (escritor argentino) y Pichuco (bandoneonista) y de Borges y Carriego (escritores) no existen como uniones de calles, sino que los siente como parte de Buenos Aires, constituyendo el alma de la ciudad, debido a la obra de estos autores.

Estás en todas. en todas las esquinas

del arrabal y el centro,

en las verdes Barrancas de Belgrano

y estás en la riberas del Riachuelo.

cuyas aguas oscuras van diciendo:

Juan de Dios Filiberto.

Vuelve a hacer referencia a las grandes diferencias barriales, mencionando una zona de alto poder adquisitivo (Belgrano) y otra marginal como la Boca, a quien se refiriera en forma permanente, Filiberto.

\section{Geografía y Folklore}


Las penas son de nosotros...

Argentina es un país con un $65 \%$ de tierras áridas, que en su mayoría son destinadas a la cría de diferentes tipos de ganado. Nuestro folklore ha dedicado un gran número de obras mostrando esta realidad, de las cuales hemos elegido El Arriero[24], por lo tradicional, lo popular y por su calidad de expresión.

En las arenas bailan los remolinos

el sol juega en el brillo del pedregal

y prendido a la magia de los caminos

el arriero va... el arriero va...

Es bandera de niebla su poncho al viento

lo saludan las flautas del pajonal

y guapeando en la senda, por esos cerros,

el arriero va... el arriero va...

En las áreas áridas donde las precipitaciones son inferiores a $200 \mathrm{~mm}$, el viento se convierte en el principal agente de erosión y su velocidad no tiene límites, mientras que los suelos son de arena y piedra, donde el sol puede reflejarse. Si bien Atahualpa Yupanqui se refiere al caso del Noroeste, estas imágenes pueden ser vistas en todas las provincias del Oeste, desde Jujuy hasta las patagónicas.

Las penas y las vaquitas,

se van por la misma senda;

las penas son de nosotros,..

las vaquitas son ajenas...[25]

Es histórica en Argentina la tenencia de la tierra en manos de grandes terratenientes que viven en las principales ciudades y dejan su ganado encargado a los peones de campo o a los arrieros, que se encargan de la trashumancia.

Un degüello de soles muestra la tarde se han dormido las luces del pedregal, y animando la tropa, dale que dale, el arriero va... el arriero va...

Amalhaya la noche traiga recuerdos que hagan menos pesada la soledad... Como sombra en la sombra por esos cerros, el arriero va... el arriero va...

Durante el atardecer, el sol forma tiras rojas en el horizonte y ya no se refleja en las piedras, las sombras comienzan a ser más largas y el arriero continúa en su travesía.

Vamos a la zafra...

Las zafras, entre ellas la azucarera, constituyen un claro ejemplo donde se emplea al grupo familiar, por el pago de una sola persona. Este ejemplo del Noroeste Argentino es expresado por Jaime Dávalos [26], de la siguiente manera: 
Vamos mi amor a la zafra

tenemos que levantar

todo el dulzor de la tierra

cuajada en las fibras del cañaveral.

De sol a sol en el surco

trabajaremos los dos

mientras madura en tu entraña

el hijo cañero que tengo con vos.

Se refiere aquí a la extensa jornada y a la participación de mujeres embarazadas. Se trata de las regiones con mayor mortalidad infantil y femenina por parto.

Quiero que tengas un chango

para yapar el jornal

porque pelando maloja

se come mis brazos el cañaveral.

En algunas poblaciones del oeste tucumano, se dictan clases durante los meses de verano, mientras que las vacaciones coinciden con los meses de junio, julio y agosto, para que los changos[27] que concurren a la zafra con sus mayores, no pierdan el ciclo escolar. Además se ve al hijo como sostén familiar en el futuro (de ahí, entre otras causas, la elevada tasa de natalidad).

Por las tardes de sol y alameda...

Por las tardes de sol y alameda

San Juan se me vuelve tonada en la voz.

y las diurnas acequias [28]

reparten el grillo de mi corazón.

$($...................................)

Volveré, volveré

a tus tardes San Juan...

Altas sombras de polvo y camino

maduran el vino de mi soledad

cuando el sol sanjuanino

como un viejo amigo me sale a encontrar.

Otra zona árida (menos de $100 \mathrm{~mm}$ anuales), pero de producción agrícola intensiva bajo riego es la región de Cuyo,[29]donde se plantan álamos para proteger las vides destinadas a la elaboración de vino.

Un poniente de largos sauzales

me busca la zamba para recordar

esas viejas leyendas

de piedra y silencio que guarda el tunal[30].

Los sauces han sido implantados a lo largo de los arroyos y acequias, mientras que en el resto del paisaje, predominan las tunas. 
Marcelo Berbel es un autor patagónico que ha dedicado una gran cantidad de temas a la realidad de nuestra región más austral, pero, sin duda, el más significativo es el que pretende una amistad con sus compatriotas del Nordeste, en su canción Del Sur al Litoral[31]:

Mi guitarra con su vuelo melodioso,

por un cielo majestuoso, rumbo al norte se me va...

$Y$ te lleva de mis bosques milenarios,

del Lanín[32] y su santuario, un saludo fraternal.

Bailan nubes que soplan vientos sureños,

de estos pagos los ensueños coloreados de michai.

$Y$ en mi verso que te canta tan lejano,

vaya mi abrazo de hermano, criollo del Litoral.

Quiero que me hables de tus paisajes y tu sol,

pues tengo una visión del Paraná.

Y quiero que conozcas a mi tierra,

con su nieve siempre eterna y su límpido Limay.

Hace referencia a las grandes diferencias entre el norte, característico por la intensidad de su sol (clima subtropical) y el caudal del río Paraná (aunque rojizo) en contraposición con la nieve (clima frío) y la transparencia del río Limay:

Llevarás las coplas de mi raza,

y yo aquí con mi guitarra cantaré a tu litoral.

En Norpatagonia, habita la comunidad mapuche, y en el Litoral, la guaraní:

Si tu vienes, matearemos en mi nido,

y en el manzanal florido, verás a tu naranjal.

En el valle del río Negro se cultivan manzanas, mientras que en la Mesopotamia, son característicos los cítricos. Pero, la costumbre de tomar mate es nacional.

$Y$ si vamos tierra dentro por mis cerros,

verás los lagos más bellos, cual es bella la Iberá

En la región cordillerana patagónica abundan los lagos tectónico-glaciarios, como el Lácar, el Nahuel Huapi, el Mascardi, el Gutiérrez, entre otros; mientras que en la provincia de Corrientes se encuentran los esteros del Iberá con una laguna en la zona central.

$Y$ diremos en la lengua de mis padres,

la mapuche, dulce y suave, algún verso guaraní.

$Y$ en tu arpa llevarás un loncomeo,

y al cantarlo allá en tu suelo, yo lo escucharé de aquí.

El loncomeo es una expresión musical patagónica, mientras que en Litoral se entonan galopas, chamamés y chamarritas. 
Quiero hacer un ramo de ceibo y amancay...

Expresa la unión a partir de las flores típicas de ambas regiones.

Yerba verde...

Este es el canto al mensú[33], trabajador del interior de Misiones, tanto en el yerbal como en el monte[34]:

Selva... noche... luna...

pena en el yerbal

el silencio vibra

en la soledad

y al latir del monte

quiebra la quietud

con el canto triste

del pobre mensú.

Neike...neike...

el grito del capanga va resonando,

neike...neike...

Río... viejo... río...

que bajando va,

quiero ir contigo

en busca de hermandad,

La provincia de Misiones se caracteriza por la cantidad de ríos y arroyos que la surcan, siendo el más importante el Paraná:

paz para mi tierra cada día más

roja con la sangre

del pobre mensú.

Compara el color de la tierra roja[35] con el color de la sangre del mensú.

Yerba... verde... yerba...

en tu inmensidad

quisiera perderme

para descansar

y en tus hojas frescas

encontrar la miel

que mitigue el surco

del látigo cruel.

Se refiere al frecuente maltrato que se recibía en los obrajes.

Cuidado el aparejo, pescador... 
El cancionero del Litoral, muy rico por cierto, está dedicado en gran parte al majestuoso y extenso río Paraná y a los modos de vida que se desarrollan en sus riberas:

Es el caso de Trasnochados Espineles, de Cholo Aguirre, quien relata lo siguiente: "Yo cantaba tangos con la orquesta de Juan Sánches Gorio. Fuimos a una gira por el litoral Argentino... Entre Ríos, Santa Fe, Corrientes, Misiones. Ahí terminábamos el contrato y me separé de ellos, porque mi deseo era comenzar en solitario. Esa misma noche un amigo me invitó a su casa en la Capital de Corrientes y me presentó a sus padres. Al día siguiente me llevaron a conocer PASO DE LA PATRIA, a unos 15 kilómetros de la casa. Bellísimo lugar, agreste, pero lleno de sol, río, selva y una gente estupenda cuyo estilo de pescar me encantó".

Yo que estuve en Paso de la Patria

donde el cielo está en la copa

de los árboles en flores.

Pude ver de cerca la esperanza

dibujándose en el rostro

de los pobres pescadores.

Llevan a flor de agua su cantar,

no ambicionan más que su existir.

"Colocaban los "espineles", que eran unos alambres de hasta 100 metros de longitud en el cual, cada diez centímetros, llevaba un anzuelo encarnado con lombrices, carne, una albondiguilla de harina, maíz y patí (un pececillo pequeño). A la mañana siguiente, desde sus canoas, iban desenganchando la pesca que había caído durante la noche."

Siglos recorriendo sin laureles

trasnochados espineles

encarnados con patí.

Por ello advierte la canción:

Cuidado el aparejo, pescador...

tal vez está enganchado un surubí...

que ganas de gritar

que yo también nací

en la ribera azul del Paraná.

El surubí es un pez de hasta 120 kilogramos de peso que, en el agua y con su peso tiene el doble de fuerza.

“Tomé apuntes de todo el entorno del lugar, me despedí de mi amigo, de sus padres y me fui. Tres años después ya era yo famoso como canta-autor en mi país. Un día, en Buenos Aires, hurgando en un cajón, me encuentro con la nota que adecenté, musiqué y grabé. Recibió varios premios y fue cantada en la película de Luis Sandrini Al Diablo con este Cura y fue considerada como La mejor canción del Litoral. A todo esto Paso de la Patria se hizo conocida por la canción y por ello, organizaron el Certamen de La Pesca del Dorado y un día me llamaron para actuar ahí. No conocí el lugar cuando llegué... estaba todo cambiado... lleno de bungalows, ajardinado, un parador de turismo de lujo. Había cambiado tanto que no era ya aquel lugar casi salvaje que yo conocí. Al entrar a actuar, había en la puerta muchas personas humildes a quienes no dejaban entrar. Micrófono en mano, saludé al público y pregunté al empresario porque no entraban los de la puerta. Porque esa gente no pinta para nada aquí!!," me contestó. 
"Pero esta es la gente a los que les dediqué mi canción, le respondí. Sí!!, pero... no tienen para pagar la entrada... Eso corre por mi cuenta, déjelos entrar..."

"No!, dijo él... el que manda aquí soy yo y no entran." "Pues si no entran... no canto!! Mientras algunas señoras orondas, enjoyadas y lujosamente vestidas salían y mis músicos guardaban sus instrumentos, el empresario se retractó y dijo... Bueno... que entren!!... Me sorprendieron porque eran como 90 personas. Se sentaron en la pista y hasta en el escenario. Cuando todo estuvo en calma yo arranqué Yo que estuve en Paso de la Patria, etc. Al finalizar los gritos, aplausos y lágrimas parecieron reventar el lugar y yo me emocioné."

Salta juguetón algún dorado, espejismo de oro y plata por la magia del verano. Toque de misterios en el río cuando se oye, como un eco, cabalgando un alarido.

Suena un acordeón en chamamé...

Paso de la Patria guaraní...

Mi cantar, en suma, es elocuente

si usted nunca fue a Corrientes

no conoce mi país.

Cuidado el aparejo, pescador...

Río abajo...

Antes del aumento del tráfico fluvial en el Paraná, los troncos de los árboles talados en los bosques misioneros, eran trasladados a la deriva por el río hasta la zona de aserraderos de las islas del Delta. A este modo de transporte se lo denominaba jangada y era llevado a cabo por un hombre, que parado encima de los troncos asidos de manera artesanal, iba guiando las maderas para que siguieran su curso. A este personaje es a quien Jaime Dávalos y Eduardo Falú le dedicaran la Canción del Jangadero:

Río abajo voy llevando la jangada

río abajo por el alto Paraná

es el peso de la sombra derrumbada

que buscando el horizonte bajará.

(...) la sombra derrumbada es una metáfora sobre la tala de árboles en la selva misionera...

Río abajo, río abajo, río abajo,

a flor de agua voy sangrando esta canción

es el sueño de la vida y el trabajo

que me vuelve camalote el corazón.

... el camalote es una planta acuática cuyas hojas tienen forma de corazón.

Jangadero... jangadero... 
mi destino sobre el río es derivar desde el fondo del obraje maderero con el anhelo del agua que se va.

...el obraje maderero es la explotación forestal en Misiones, tierra del mensú.

Padre río, tus escamas de oro vivo son el sueño que nos llevan mas allá vamos tras el horizonte fugitivo y la sangre con el agua se nos va.

... las escamas de oro vivo son el reflejo del sol en el Paraná y la sangre es el color rojo del río, que carga con los sedimentos de las tierras de Misiones.

Banda a banda, sol y luna, cielo y agua espejismo que no acaba de pasar piel de barro, fabulosa lampalagua me devora la pasión de navegar. Jangadero... jangadero...

Banda a banda, los troncos derivan de una ribera a la otra del río; sol y luna, día y noche; cielo y agua, monotonía de colores...

La lampalagua es una víbora de gran tamaño color marrón que se mimetiza con los suelos ribereños.

Padre de las frutas y las maderas...

El Paraná en una Zamba, es otra de las manifestaciones folklóricas de Jaime Dávalos y Ariel Ramírez que constituye una excelente obra geográfica:

Brazo de la luna que bajo el sol el cielo y el agua rejuntará

hijo de las cumbres y de las selvas que extenso y dulce recibe el mar.

El Paraná es un extenso hilo de plata que se desplaza desde los morros y selvas de Brasil hasta el mar a través del río de la Plata.

Sangra en tus riberas el ceibo en flor y la pampa verde llega a beber en tu cuerpo lacio donde el verano despeña toros de barro y miel.

El ceibo, que se encuentra a lo largo de sus riberas es de color rojo intenso y es la flor nacional de la Argentina. El río llega hasta la región pampeana donde abundan los verdes pastizales.

Mojan las guitarras tu corazón que por los trigales ondulará 
traen desde el Norte frutal la zamba

y a tus orillas la dejarán

para que tu voz enamorada de la luz carnal

arome tus mujeres Paraná.

En campos de lino recobrarás

el cielo que buscas en la extensión

padre de las frutas y las maderas

florece en deltas tu corazón.

El río se desplaza por la provincia de Santa Fe y Buenos Aires, donde se siembra trigo y lino, pero arrastra desde otras latitudes, frutales que caen a él y que el río deposita en su desembocadura en forma de delta.

Verde en el origen recorrerás

turbio de trabajo la noche azul

$y$ desde la luna como un camino

vendrá tu brillo quebrando luz.

El Alto Paraná es de color verde por el reflejo de la vegetación selvática, mientras que luego cambia de color. Pero a la noche, la luna se refleja formando extensas líneas transversales...

\section{Otras obras del folklore argentino}

Paisaje de Catamarca, de Polo Jiménez, Puerto de Santa Cruz, de Horacio Guaraní, están entre las tantas obras de nuestro folklore que transmiten a todo tipo de público la Geografía de nuestro país.

Ampelio Liberali ha realizado un audiovisual denominado "Argentina de Punta a Punta",donde seleccionó una canción descriptiva de cada provincia, constituyendo un trabajo de Geografía Regional.

\section{OTROS GEÓGRAFOS SIN TOGA}

¿Qué importa el río ni la vejez ni la novedad? Digo dos ciudades como en toda ciudad del mundo: una para el que llega con dinero, y otra para el que llega como nosotros. (Palabras de Crispín, en Los Intereses Creados de Jacinto Benavente)

Muchos son los geógrafos que no usan toga y que enseñan sin pizarrón.

Humboldt lo ha hecho a partir de sus relatos de viajes, destacándose por la importancia literaria de sus escritos, además de su profundidad científica. Pero otros no han tenido esa preparación académica como para poder lograr esa armonía humboldtiana. Sin embargo, son sus obras verdaderos textos de Geografía. 
En el campo de la literatura, es el caso de José Hernández en el Martín Fierro, Horacio Quiroga en Anaconda o El Muerto, Sixto Vázquez Zuleta en sus cuentos de la Quebrada de Humahuaca, Roberto Arlt y Marco Denevi en sus novelas sobre los barrios de Buenos Aires, etc.

Relatos como los de Luis Landriscina constituyen excelentes descripciones geográficas donde convergen aspectos físicos, sociales y económicos, con especial referencia a la Geografía Cultural.

Pintores como Quinquela Martín quien refleja la vida en las riberas del Riachuelo, destacando las duras condiciones del trabajo y la inundación...

O audiovisuales como El Partido que nadie ve de Ampelio Liberali, que muestra las actividades concatenadas derivadas de un partido entre River y Boca..., constituye una muestra de Geografía Económica.

\section{CONCLUSIONES}

La intención es afirmar que no solamente se pueden incorporar al aula los recursos mencionados, sino que se puede enseñar Geografía fuera del aula.

Tampoco es necesario un geógrafo o profesor de Geografía para hacerlo, sino que sin proponérselo, tanto artistas como periodistas, pueden contribuir directa o indirectamente a la enseñanza de nuestra disciplina.

De todos modos, la mejor forma de aprender Geografía es visitando cada lugar, porque como afirmara José de Ortega y Gasset "Lo real rebasa siempre al concepto que lo intenta contener".

\section{NOTAS}

[1] FULL MONTY, Directed by Peter Cattaneo. Twentieth Century Fox Film Corporation, Released 1997.

[2] Tocando el Viento (Brassed Off). Gran Bretaña, 1996. Dirección y guión: Mark Herman. Música: Trevor Jones.

[3] De Adolfo Aristarain (1992).

[4] De Miguel Pereira (1988): En Chorcán, Jujuy, un joven indígena conoce a un maestro rural recién llegado de la Capital Federal. Nace una amistad que se interrumpe cuando al joven le toca el servicio militar y es convocado a participar en la Guerra de Malvinas.

[5] Gran parte de quienes fueron llamados para pelear en esa guerra inútil y desigual, eran jóvenes de las zonas más pobres de nuestro país, huérfanos en lo posible, para que nadie pudiera hacer reclamos de ninguna naturaleza.

[6] La película "Tráfico" muestra una imagen devastadora de la guerra contra las drogas. Su director, Steven Soderbergh, pone a un lado la hipócrita gazmoñería gubernamental y lanza rebeldemente esta pregunta: ¿contra quién va dirigida la guerra contra las drogas? 
[7] De Jaime Uys (1980).

[8] De Peter Chappell, Inglaterra 1997.

[9] PUEBLO BLANCO. Letra y música de Juan Manuel Serrat.

[10] Él es quien años después moriría en el hundimiento del Gral. Belgrano.

[11] MEDITERRÁNEO. Letra y música de Juan Manuel Serrat.

[12] Este sentimiento es característico de los inmigrantes europeos en América.

[13] AMARRAS. Letra de Carmelo Santiago. Musica de C. Marchisio

[14] Se refiere a la recova de la Av. Paseo Colón (Buenos Aires), denominada popularmente el Bajo, hasta donde llegaba el río de la Plata antes de las obras ingenieriles que lo desplazaron.

[15] La imposibilidad de partir sigue presente en el espíritu de gran parte de los argentinos.

[16] De Homero Manzi y Aníbal Troilo.

[17] Cobian y Cadicamo.

[18] Letra de Homero Manzi y música de Aníbal Troilo.

[19] De Piazzola, cantado por Amelita Baltar.

[20] De Cacho Castaña.

[21] De Eladia Blázquez.

[22] EN QUE ESQUINA TE ENCUENTRO BUENOS AIRES? Letra de Florencio ESCARDO y Música de Héctor Stamponi.

[23] Principal teatro municipal con espectáculos y escuelas de teatro, cine, música y canto.

[24] Letra y música de Atahualpa Yupanqui.

[25] En la versión original decía "las vaquitas son de Anchorena".

[26] Vamos a la zafra. Letra de Jaime Dávalos y Música de Eduardo Falú.

[27] Modo de denominar a los niños y jóvenes en el Noroeste Argentino.

[28] Canales de riego.

[29] Volveré siempre a San Juan. Letra de A. Tejada Gomez y Música de Ariel Ramírez.

[30] Conjunto de tunas, vegetación xerófila.

[31] Del Sur al Litoral. Letra y música de Marcelo Berbel.

[32] Volcán de la provincia de Neuquen.

[33] EL MENSU (GALOPA) Letra de Ramón Ayala y música de José Vicente Cidade.

[34] Bosque subtropical.

[35] Suelos lateríticos. 
